\title{
Human Memory Th17 Cells Express a Functional Histamine H4 Receptor
}

\author{
Susanne Mommert, Maria Gschwandtner, \\ Brigitta Koether, Ralf Gutzmer, and \\ Thomas Werfel
}

From the Division of Immunodermatology and Allergy Research, Department of Dermatology and Allergy, Hannover Medical School, Hannover, Germany

The histamine $\mathrm{H} 4$ receptor is functionally expressed on $\mathrm{CD}^{+}{ }^{+} \mathrm{T}$ cells and in particular on human $\mathrm{CD}^{+}$ Th2-polarized T cells. Interleukin (IL)-17-producing $T$ cells (Th17 cells) represent a newly defined major $\mathrm{CD}^{+} \mathrm{T}$-cell subset, having been identified in psoriatic plaques and in acute skin lesions of atopic dermatitis where histamine is also present in high concentrations. To elucidate the role of the histamine $\mathrm{H} 4$ receptor (H4R) on these effector T cells, we polarized human memory $\mathrm{T}$ cells into Th17 cells. Further, we investigated $\mathrm{H}$ 4R expression and assessed its function by real-time PCR, by a cytokine secretion assay of IL-17, and by electrophoretic mobility shift assay of activating protein-1 (AP-1). We show that Th17 cells polarized by IL-1 $\beta$ together with IL-23 express the H4R on mRNA and protein level. Additionally, we identified IL-17-positive cells in psoriatic skin lesions. The IL-17-positive lymphocytes were all positive also for functional H4R. Stimulation with histamine or a $H 4 R$ agonist increased the production of IL-17 and induced activating protein- 1 in Th17 cells. In inflammatory skin diseases with enhanced histamine release, such as psoriasis and atopic dermatitis, histamine might foster the immunomodulatory potency of skin-infiltrating Th17 cells. (AmJ Pathol 2012, 180:177-185; DOI: 10.1016/j.ajpath.2011.09.028)

Histamine is a multifunctional biological amine with diverse activities in the immune system. During inflammation, histamine is released from preformed stores in mast cells and basophils. The effects of histamine are mediated through four known $G$ protein-coupled receptors. The H4R is the most recently identified of the four histamine receptors and is expressed in tissues and cells of the immune system, such as the spleen, thymus, bone marrow, and, preferentially, in leukocytes. ${ }^{1,2}$ Several activities of the H4R on cells involved in inflammatory responses have been investigated so far. Chemotaxis of mast cells, eosinophils, monocyte-derived dendritic cells, and natural killer cells have been noted via the H4R. ${ }^{3-6}$ In previous studies we observed functional effects of H4R on cells involved in inflammatory and allergic diseases such as human monocyte-derived dendritic cells, ${ }^{5}$ slan-dendritic cells (dendritic cells bearing a 6-sulfo LacNAc group on their surface), ${ }^{7}$ monocytes, ${ }^{8}$ and Langerhans cells. ${ }^{9}$ Furthermore, we showed that the H4R is up-regulated under Th2 conditions on human $T$ cells. The stimulation of Th2 cells via the H4R leads to the activation of activating protein-1 (AP-1) and to an increase of IL-31 mRNA. ${ }^{10}$

Although Th1 and Th2 cells have long been implicated in the pathogenesis of inflammatory diseases, Th17 cells recently gained attention as a newly delineated subset of $\mathrm{CD}^{+} \mathrm{T}$ cells in this context. Th17 cells are characterized by the production of the interleukin IL-17A (referred to simply as IL-17) and by the expression of the transcription factor retinoic acid receptor-related orphan receptor (ROR), RORyt, and RORC in mice and humans respectively.

Th17 cells are thought to be key players in the pathogenesis of psoriasis. Indeed, Th17 cells are markedly abundant in psoriasis lesions. ${ }^{11,12}$ Also, primary circulating Th17 cells (identified by combining expression of the characteristic surface markers CCR6 and intracellular IL-17 production) are increased in psoriasis. ${ }^{13}$ Furthermore, Th17 cells preferentially infiltrate acute eczematous lesions of patients with atopic dermatitis $(A D)^{14-16}$; however, compared with psoriasis there is a lesser extent of IL-17 expression in lesional skin. ${ }^{17}$ The cytokines produced by Th17 cells, in particular IL-17 have been directly linked to the regulation of proteins involved in in-

Supported by grants from the Deutsche Forschungsgemeinschaft; DFG (Gu 434/5-2), DFG (SFB566 A6) and the European Community (COST action BM0806).

Accepted for publication September 28, 2011.

Address reprint requests to Susanne Mommert, M.Sc., Division of Immunodermatology and Allergy Research, Department of Dermatology and Allergy, Hannover Medical School, Carl-Neuberg-Str. 1, D-30625 Hannover, Germany. E-mail: Mommert.Susanne@mh-hannover.de. 
nate immune system as they trigger keratinocytes to produce antimicrobial peptides to modulate host defenses. ${ }^{16,18}$ They also promote immune cells to secrete a panel of chemokines and pro-inflammatory cytokines, ${ }^{15}$ which allow Th17 cells to communicate with a wide variety of immune and nonimmune cells and to regulate their function. Intriguingly, despite increased levels of IL-17 in $\mathrm{AD}$ and consistent expression of $\mathrm{IL}-17$ receptor compared with normal skin, a decrease of defense molecule expression, which is attributed to a more Th2-pronounced microenvironment, which antagonizes the IL-17 effect has been shown in AD. ${ }^{19}$

To obtain insight into inflammatory skin diseases where histamine and Th17 cells are present in affected tissue, we wanted to elucidate whether histamine can influence the activity of this newly defined effector T cells, in particular via the H4R. In the present work, we used the cytokine combinations tumor growth factor- $\beta$ (TGF$\beta)+I L-6$ or IL-1 $\beta+I L-23$ to polarize human memory T cells into Th17 cells. In agreement with previous reports, ${ }^{12,20,21}$ we could show that $|\mathrm{L}-1| \beta$ together with IL-23 induces the largest amount of IL-17 secretion. We then demonstrated that in vitro polarized Th17 cells as well as IL-17-positive lymphocytes in lesions of psoriasis express the H4R. Next, the capacity of polarized memory Th17 cells was analyzed to produce Th17 specific effector cytokines and signaling molecules in response to histamine and H4R agonists. The interaction of Th17 cells with histamine observed in this study provides a new process which may influence the pathology of psoriasis and $A D$.

\section{Materials and Methods}

\section{T Cell Isolation, Stimulation, and Polarization}

Buffy coats that were disposed by the blood bank after thrombocyte preparation from anonymous healthy blood donors were used. Human peripheral blood mononuclear cells were separated from buffy coats by density gradient centrifugation on lymphoprep (Fresenius Kabi Norge AS, Oslo, Norway). $\mathrm{CD} 4^{+} \mathrm{T}$ cells and $\mathrm{CD} 4^{+} \mathrm{CD} 45 \mathrm{RO}{ }^{+} \mathrm{T}$ cells were isolated using magnetic beads according to the manufacturer's instructions (Miltenyi Biotech Inc., Bergisch-Gladbach, Germany). T cells were cultured in modified Iscove medium (called IAB medium hereafter) that was supplemented with $A B$ serum $(5 \% \mathrm{v} / \mathrm{v})$, nonessential amino acids (1\% w/v), I-glutamine (1\% w/v), penicillin/ streptomycin $(1 \% \mathrm{w} / \mathrm{v})$, and gentamicin $(0.5 \% \mathrm{w} / \mathrm{v})$ at $37^{\circ} \mathrm{C}$ in a humidified atmosphere at $5 \% \mathrm{CO}_{2}$.

For polarization of memory T cells into Th17 cells, $1 \times$ $10^{6}$ isolated memory $\mathrm{CD} 4^{+} \mathrm{T}$ cells $/ \mathrm{mL}$ were resuspended in $\mathrm{IAB}$ medium, transferred to 96-well round bottom plates $(200 \mu \mathrm{L} /$ well) and stimulated with activating antiCD3 $(5.5 \mu \mathrm{g} / \mathrm{mL})$ and anti-CD28 $(1 \mu \mathrm{g} / \mathrm{mL})$ antibodies (Pelicluster, Amsterdam, The Netherlands). For polarization of Th17 cells, the combinations TGF- $\beta$ ( $1 \mathrm{ng} / \mathrm{mL}$; Promocell, Heidelberg, Germany) and IL-6 (40 ng/mL; Immunotools, Friesoythe, Germany), or $\mathrm{IL}-1 \beta$ (10 ng/mL; Peprotech, Offenbach, Germany) and IL-23 (50 ng/mL,
R\&D Systems, Wiesbaden, Germany) were added to the cultures. Every 3 to 4 days, the medium was completely changed, after 10 to 12 days cells were used for experiments. For control of proper polarization, relative IL-17 mRNA expression levels were calculated by quantitative real-time PCR, in addition a portion of all subtypes of cells were restimulated with phorbol 12-myristate 13 acetate (PMA) and ionomycin (Sigma Aldrich, Deisenhofen, Germany) for 5 hours followed by intracellular flow cytometric staining of IL-17. Polarized Th17 cells differentiated by IL-1 $\beta+$ IL-23 showed clear expression of IL-17.

\section{Histamine Receptor Ligands}

Histamine (Hist) was obtained from Alk-Scherax (Wedel, Germany), 4-methylhistamine $(4 \mathrm{MH})$ was obtained from Tocris Bioscience (Bristol, United Kingdom). The H1R antagonist Clemastine was delivered by Novartis (Nürnberg, Germany), the H2R antagonist Ranitidine was from Biomol (Hamburg, Germany), and the H4R antagonist JNJ7777120 was obtained from Sigma Aldrich. All histamine receptor ligands were used at a concentration of $10^{-5} \mathrm{M}$.

\section{Real-Time Quantitative LightCycler RT-PCR}

Activated and memory Th17 cells were resuspended at $2 \times 10^{5}$ cells $/ 200 \mu \mathrm{L}$ in IAB medium. Depending on the experiment, RNA was immediately isolated or cells were stimulated for 6 hours with different stimuli as indicated. For blocking experiments the cells were treated with the H1R antagonist Clemastine, the H2R antagonist Ranitidine, and the H4R antagonist JNJ7777120 for 30 minutes before histamine stimulation. Total RNA was isolated according to the manufacturer's instructions with the Mini RNA Isolation II Kit (Zymo Research, Orange, CA). The cDNA was synthesized by reverse transcription (MBI Fermentas, St. Leon-Rot, Germany) or in the case where both primers are located in the same exon, genomic DNA was removed using the Quantitect reverse transcription kit (Qiagen, Hilden, Germany). As control, to show reliability of H3R PCR in absence of the expression of the H3R on Th17 cells, complementary DNA of H3R-transfected human embryonic kidney cells (HEK cells) was prepared analogously and amplified. Real-time quantitative LightCycler PCR (Roche Molecular Biochemicals, Mannheim, Germany) was performed with Quantitect primer assay for H1R (QT00199857), H2R (QT00210378), H3R (QT00210861), H4R (QT00032326), IL-17 (QT00009233), IL-22 (QT00034853), RORC (QT00097888), and glyceraldehyde-3-phosphate-dehydrogenase (GAPDH; QT01192646) using SYBR Green according to the manufacturer's instructions (Qiagen).

The amount of the target mRNA relative to the amount of the reference GAPDH mRNA in the same sample was calculated using the Relative Quantification Software (Roche Molecular Biochemicals). HxR and GAPDH PCR products were subjected to electrophoresis on a $2 \%$ agarose gel (Roth, Karlsruhe, Germany) in 1× Tris-BorateEDTA buffer (Roth), stained with gel-star (Biozym, Hessisch, 
Oldendorf, Germany), visualized and photographed under ultraviolet illumination.

\section{Flow Cytometric Analysis}

Activated and memory Th17 cells were stained according to the protocol and with the reagents provided by BD Biosciences (Becton Dickinson, Heidelberg, Germany) for intracellular epitope-directed antibodies. Intracellular IL-17 staining was performed after restimulation with PMA and ionomycin for 5 hours in the presence of monensin. For the H4R staining cells were left unstimulated. Cells were fixed, made permeable, and a monoclonal antibody for IL-17 (eBioscience, San Diego, CA) or the respective isotype control (BD Biosciences) was applied. For the H4R staining, a rabbit polyclonal antibody (Santa Cruz Biotechnology, Santa Cruz, CA) or a polyclonal rabbit isotype control (R\&D Systems, Wiesbaden, Germany) was used followed by labeling with goat antirabbit fluorescein isothiocyanate (FITC) (Beckman Coulter, Krefeld, Germany). Stained cells were washed three times, resuspended in PBS and quantified by flow cytometry (FACS Calibur; Becton Dickinson).

\section{Immunofluorescence Staining of Th17 Cells Expressing H4R}

Skin biopsies derived from patients diagnosed with psoriasis were fixed in 10\% phosphate buffered formalde- hyde. After paraffin embedding, samples were cut into $5-\mu \mathrm{m}$ sections, mounted on glass slides, and treated for deparaffination. An antigen retrieval procedure was performed by incubation overnight in Target Retrieval Solution (Dako Cytomation, Glostrup, Denmark) at $70^{\circ} \mathrm{C}$. Blocking of nonspecific binding sites was then performed using PBS containing 0.2\% Triton X-100 (Sigma Aldrich), $0.02 \%$ sodium azide (Merck, Darmstadt, Germany), and $5 \%$ normal goat serum for 1 hour at room temperature. Following this, the slides were stained with anti-IL-17 (eBioscience) or mouse IgG1 (BD Biosciences), and anti-H4R (Santa Cruz Biotechnology) or rabbit IgG (R\&D Systems) diluted in REAL antibody diluent (Dako) overnight at $4^{\circ} \mathrm{C}$. After a subsequent washing in PBS, appropriate fluorescein (FITC)-conjugated goat antimouse and Texas Red dye-conjugated goat antirabbit secondary antibodies (Jackson ImmunoResearch Europe, Suffolk, UK) diluted 1:200 in REAL antibody diluent were applied for 2 hours at room temperature. Fluorescence images were obtained with a Zeiss Axiolab microscope with AxioCam MRm (Carl Zeiss Microlmaging GmbH, Göttingen, Germany), and images were acquired with the program AxioVS40 (version 4.6.1.0) (Carl Zeiss Microlmaging $\mathrm{GmbH}$ ).

\section{IL-17 Secretion Assay}

Th17 cells were plated in IAB Medium in 96-well plates (2 to $5 \times 10^{5} /$ well/200 $\mu \mathrm{L}$ ) and stimulated with the indicated histamine receptor ligands $(10 \mu \mathrm{mol} / \mathrm{L})$ for 2 hours, then
A

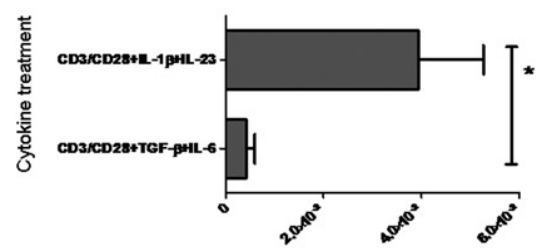

IL-17 mRNA normalized ratio

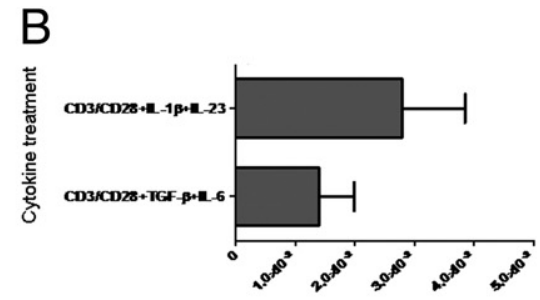

IL-22 mRNA normalized ratio

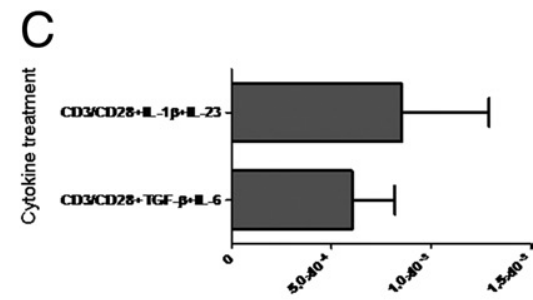

RORC mRNA normalized ratio

D

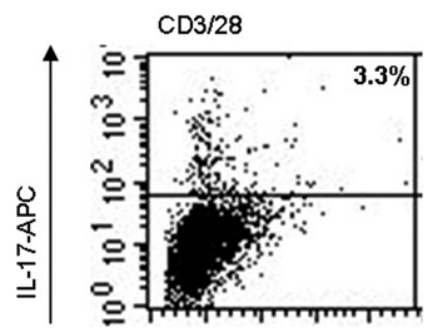

CD3/28+TGF- $\beta+$ IL 6

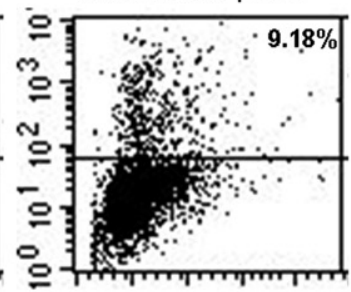

CD3/28+IL-1 $\beta+I L-23$

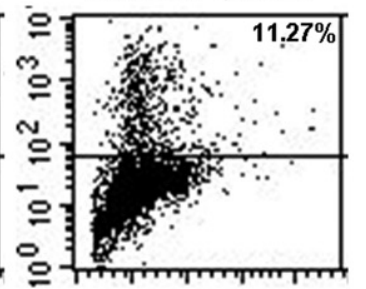

Forward Scatter

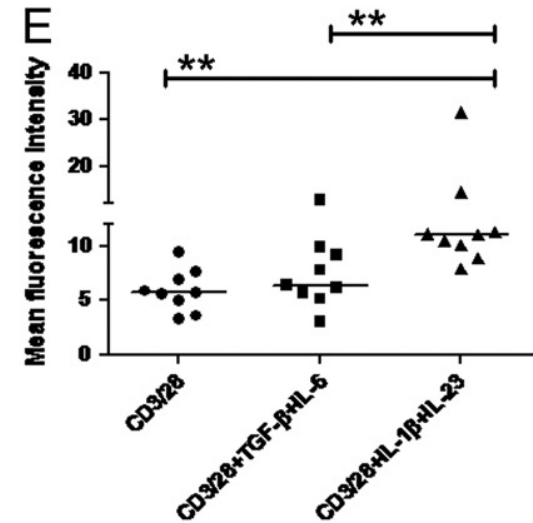

Figure 1. IL- $1 \beta+\mathrm{IL}-23$ induce Th17 differentiation from memory $\mathrm{CD} 4{ }^{+} \mathrm{CD} 45 \mathrm{RO}{ }^{+} \mathrm{T}$ cells, which is characterized by an increased expression of the effector cytokines IL-17 and IL-22. CD ${ }^{+} \mathrm{CD} 45 \mathrm{RO}^{+} \mathrm{T}$ cells were isolated from peripheral blood mononuclear cells and stimulated with the indicated cytokines for 12 days. Real-time PCRs show expression levels of (A) IL-17 mRNA, (B) IL-22 mRNA, and (C) and retinoic acid receptor-related orphan receptor (RORC) mRNA; mean and SEM of (A) seven or ( $\mathbf{B}$ and $\mathbf{C})$ eight independent experiments are shown. Gyceraldehyde-3-phosphate-dehydrogenase (GAPDH) was used as reference gene. D: For IL-17 analysis on the protein level the cells were stimulated as indicated and intracellular IL-17 staining was performed and measured by flow cytometry, percentages of IL-17 positive cells are stated in the dot blots. E: Depiction of a summary of all performed experiments (medians for nine independent experiments are indicated). APC, Allophycocyanin. 
A

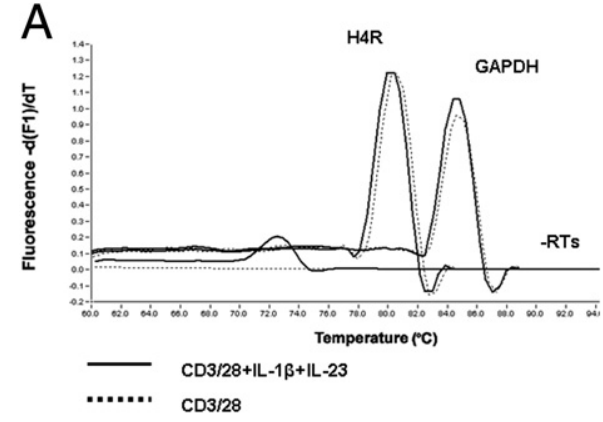

C

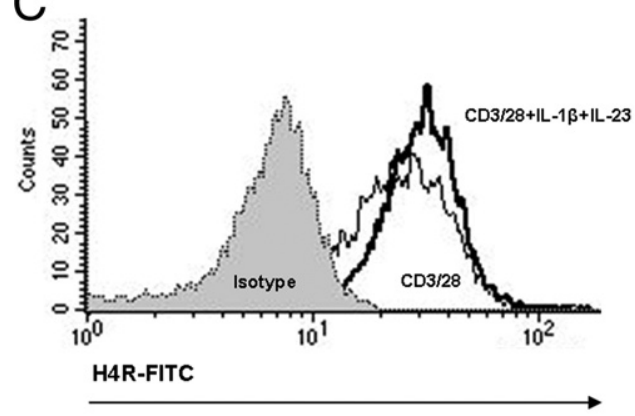

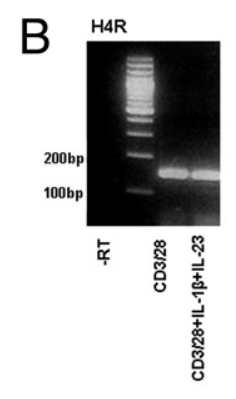

D

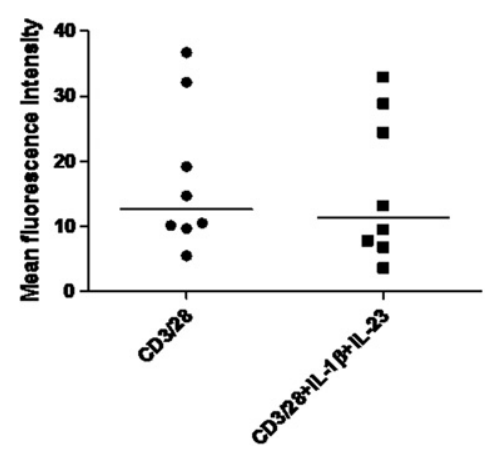

Figure 2. H4R is expressed on activated $\mathrm{T}$ cells and memory Th17 cells on mRNA and protein level. One representative real-time LightCycler PCR experiment out of three with the specific melting peaks for the H4R and glyceraldehyde3-phosphate-dehydrogenase (GAPDH) (A) and one representative agarose gel out of three with the amplified PCR products of H4R (130 bp) and GAPDH (119 bp) (B) are shown (-RT is a negative control without reverse transcription). One representative flow-cytometric experiment showing H4R staining on activated T cells and memory Th17 cells compared with isotype staining $(\mathbf{C})$ and a summary of $n=8$ independent experiments showing the mean fluorescence intensity values (D) are shown.
Staphylococcal enterotoxin B (SEB; Toxin Technology Inc, Sarasota, FL) was added for another 16 hours. For blocking experiments the cells were treated with the H1R antagonist Clemastine, the $\mathrm{H} 2 \mathrm{R}$ antagonist Ranitidine, and the H4R antagonist JNJ7777120 for 30 minutes before histamine stimulation. IL-17 secreting cells were detected using the IL-17 secretion assay (Miltenyi Biotec) according to the manufacturer's instructions. The secreted IL-17, bound to the catch reagent, was stained with $10 \mu \mathrm{L}$ Allophycocyanin-conjugated IL-17 specific antibody (IL-17 Detection Reagent) and the surface was stained with anti-CD4-FITC (Beckman Coulter) and anti-CCR6-PE (BD Biosciences). Up to 120000 cells were acquired by flow cytometry from the stimu-

\section{IL-17 FITC}

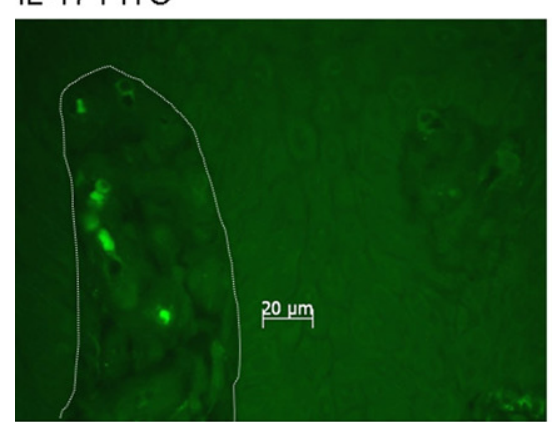

\section{H4R Texas Red}

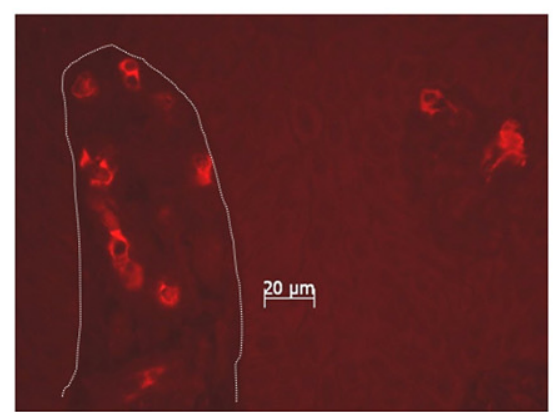

\section{$\mathrm{IL}-17+\mathrm{H} 4 \mathrm{R}$}

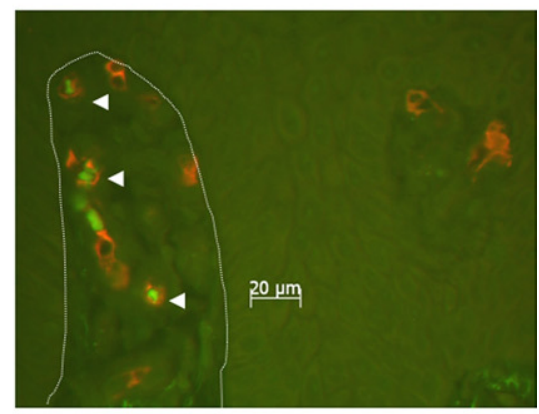

isotype controls
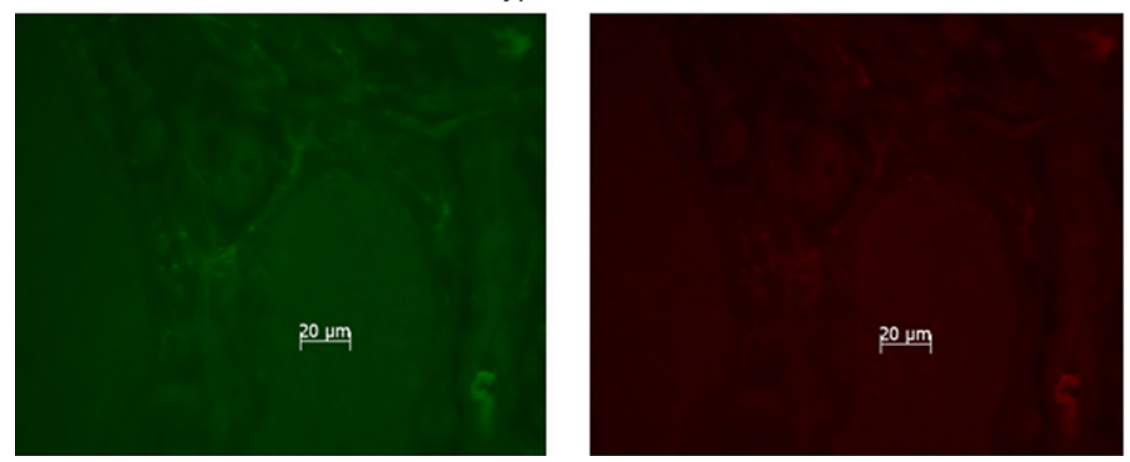

Figure 3. $\mathrm{H} 4 \mathrm{R}$ is expressed in situ on infiltrating IL-17 positive cells in psoriasis. Double immunofluorescence staining in skin lesions from psoriasis patients with anti-IL-17 (FITC) and anti-H4R (Texas-Red) shows co-localization of $\mathrm{H} 4 \mathrm{R}$ on IL-17 positive cells (FITC + Texas-Red) (arrowheads). Scale bars $=20 \mu \mathrm{m}$. The location of the basement membrane is indicated by the white scattered line. One representative result out of four experiments is shown. 

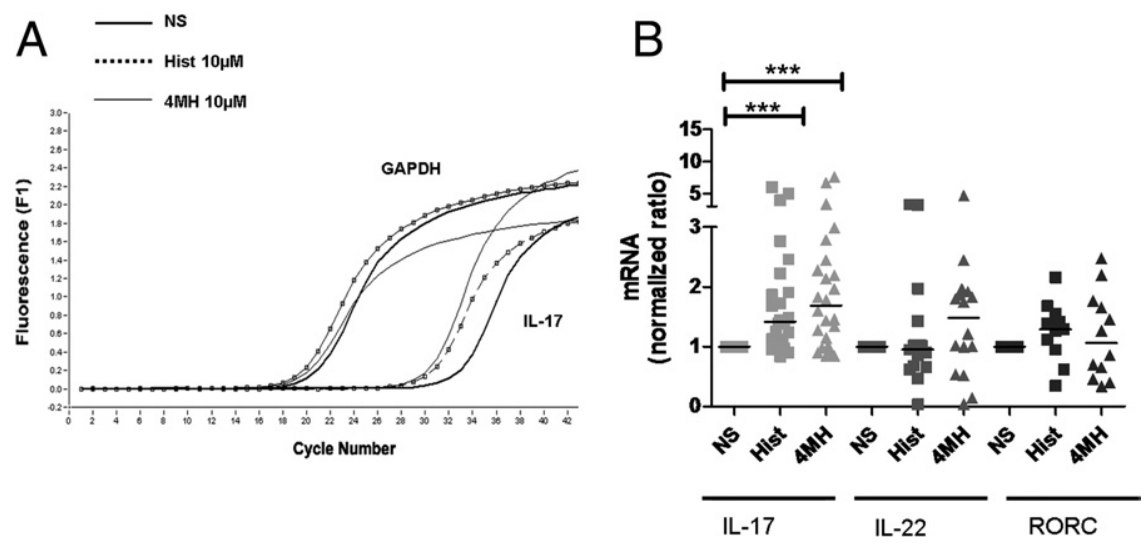

Figure 4. Histamine and the H4R agonist $4 \mathrm{MH}$ significantly up-regulate IL-17 mRNA, whereas IL-22 and retinoic acid receptor-related orphan receptor (RORC) mRNA are not regulated by these histamine receptor ligands. A: Amplification curves of IL-17 and glyceraldehyde-3-phosphate-dehydrogenase (GAPDH), nonstimulated (NS) (black line) versus histamine (Hist) (dotted line) and 4MH (gray line) treated Th17 cells are depicted. B: Relative expression levels of IL-17 mRNA ( $n=24)$, IL-22 mRNA ( $n=15$ to 16$)$, and RORC mRNA ( $n=11$ to 12 ) were normalized to GAPDH mRNA and expressed as fold induction compared with the untreated cells (medians are indicated).

lated as well as from the unstimulated samples. A lymphocyte gate based on $\mathrm{CD}^{+}$and $\mathrm{CCR}^{+}$staining was activated.

\section{Electrophoretic Mobility Shift Assay for AP-1}

Cells were stimulated with the indicated stimuli (10 $\mu \mathrm{mol} / \mathrm{L})$ for 30 minutes, nuclear extracts were performed according to the manufacturer's instructions using the N-PER Nuclear Extraction Kit (Thermo Fisher Scientific Germany, Bonn, Germany). Electrophoretic mobility shift assays (EMSAs) for AP-1 (activating protein-1) were performed as described previously. ${ }^{5,10}$

\section{Statistical Analysis}

For statistical analyses the software GraphPad Prism Version 5.0 (GraphPad Software, La Jolla, CA) was used. To compare paired values, a normality test was performed first. In case the normality test was passed, a paired $t$-test was performed and the mean value is shown in the graphs. In case the normality test failed, a Wilcoxon signed rank test was performed and the median is shown in the graph. A $P<0.05$ was regarded as statistically significant $(P<0.05$ was labeled with $*, P<0.01$ was labeled with $* *$, and $P<$ 0.0005 was labeled with $* * *$ ).

\section{Results}

\section{IL-1 $\beta$ in Combination with IL-23 Promotes Th17 Differentiation from Human Memory T Cells}

To differentiate $\mathrm{CD} 4^{+}$memory $\mathrm{T}$ cells into Th17 cells, we first isolated human $\mathrm{CD} 4^{+} \mathrm{CD} 45 \mathrm{RO}^{+} \mathrm{T}$ cells. The cells were cultured and activated by crosslinking the $\mathrm{T}$ cell receptor and CD28 receptor and stimulated with two different cytokine combinations to polarize memory $\mathrm{T}$
A

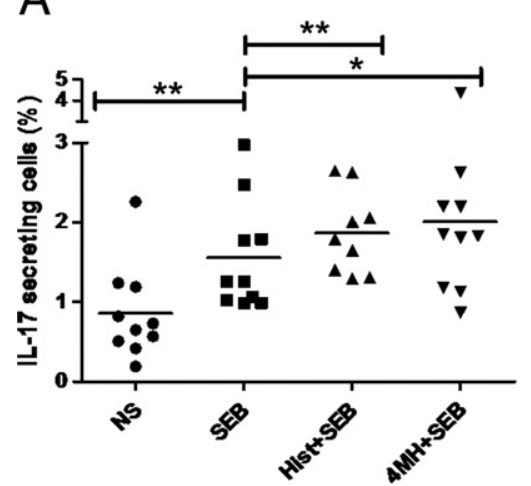

Figure 5. Histamine and the H4R agonist $4 \mathrm{MH}$ significantly up-regulate IL-17 protein secretion in memory Th17 cells as assessed by the cytokine secretion assay via flow cytometry. Th17 cells were left unstimulated (NS) (circles) or were stimulated with SEB $(1 \mu \mathrm{g} / \mathrm{mL})$ (squares) or SEB in combination with histamine (Hist) (up-triangle) or $4 \mathrm{MH}$ (10 $\mu \mathrm{mol} / \mathrm{L}$ ) (down-triangle). Quadrant plot analysis with the percentage of IL-17 secreting cells is shown. A: Medians of 9 or 10 independent experiments are indicated. B: One representative experiment is shown. The lymphocyte gate is based on CD4-FITC and CCR6-PE staining. APC, Allophycocyanin. ${ }^{*} P<$ $0.05,{ }^{\text {* *k }} P<0.01$.
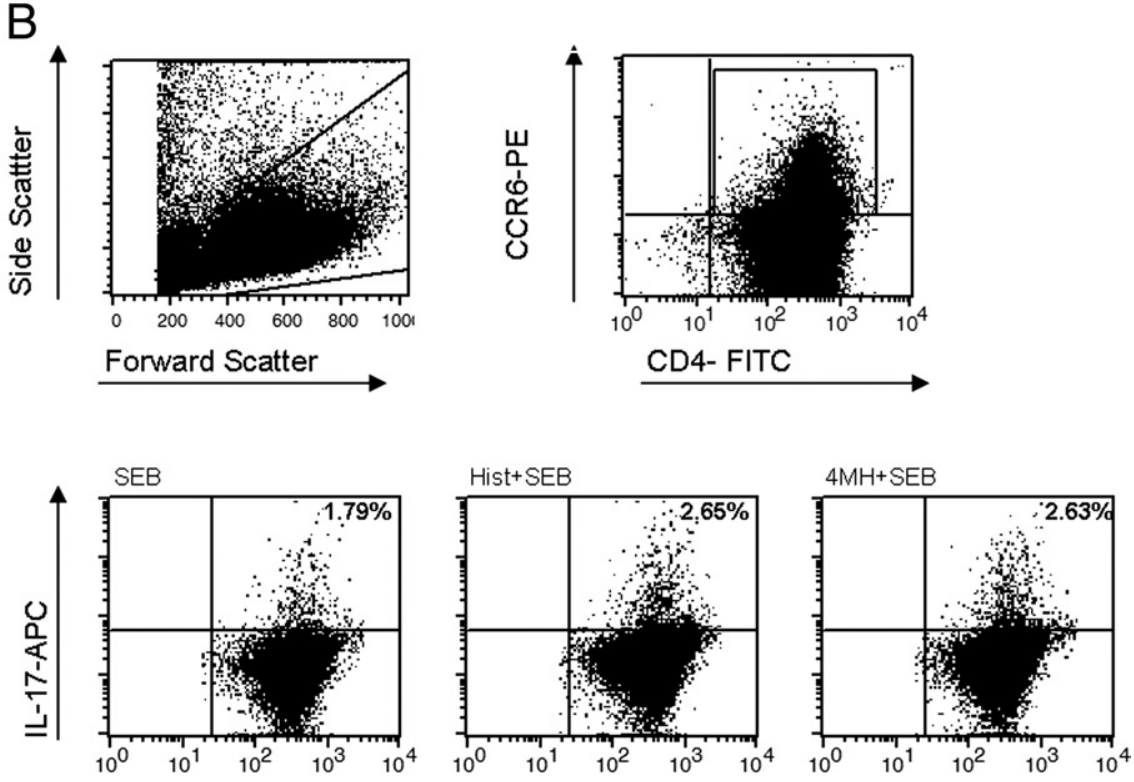

CD4-FITC 
cells into Th17 cells - TGF- $\beta+$ IL- 6 or IL- $1 \beta+\mathrm{IL}-23$. The mRNA expression of the effector cytokines IL-17, IL-22, and of the Th17-specific transcription factor RORC were measured by means of quantitative real-time PCR. The memory T-cell subpopulation stimulated with IL$1 \beta+\mathrm{IL}-23$ showed a significant increase of IL-17 mRNA (Figure 1A) and a twofold increase of IL-22 mRNA (Figure $1 \mathrm{~B})$, compared with the subpopulation stimulated by TGF- $\beta+$ IL-6. Only a modest difference of expression of RORC mRNA was observed between these two subsets (Figure 1C). Intracellular IL-17 staining was performed to corroborate the mRNA data (Figure 1D), a summary of nine independent experiments is shown in Figure 1E. Confirming the results on mRNA level, the memory $T$ cells stimulated with IL-1 $\beta+\mathrm{IL}-23$ secreted more IL-17 protein than did the memory T cells stimulated with TGF- $\beta+\mathrm{IL}-6$. Moreover, flow cytometric analysis revealed increased expression of CCR6 and HLA-DR on the cells treated with $\mathrm{IL}-1 \beta+\mathrm{IL}-23$ (data not shown). Therefore, the cells differ- entiated with IL-1 $\beta+\mathrm{IL}-23$ were identified as the principal IL-17 secreting $\mathrm{CD} 4{ }^{+} \mathrm{CD} 45 \mathrm{RO}^{+} \mathrm{T}$ cells and used for further experiments (termed Th17 cells hereafter).

\section{H4R Is Expressed on Human Memory Th17 Cells}

$\mathrm{CD}^{+} \mathrm{T}$ cells and especially Th2 polarized $\mathrm{T}$ cells have been shown to express the H4R on mRNA and protein level, as described by us recently. ${ }^{10}$ To evaluate the expression of the H4R on Th17 cells, real-time PCR using primers specific for the H4R was performed for activated T cells and memory Th17 cells. The amplified products were analyzed by LightCycler melting curve analysis revealing specific melting peaks at $79.70^{\circ} \mathrm{C}$ (Figure 2A) and by agarose gel electrophoresis where sharp bands in the expected size could be demonstrated (Figure 2B). We could also show the expression of the H4R on protein
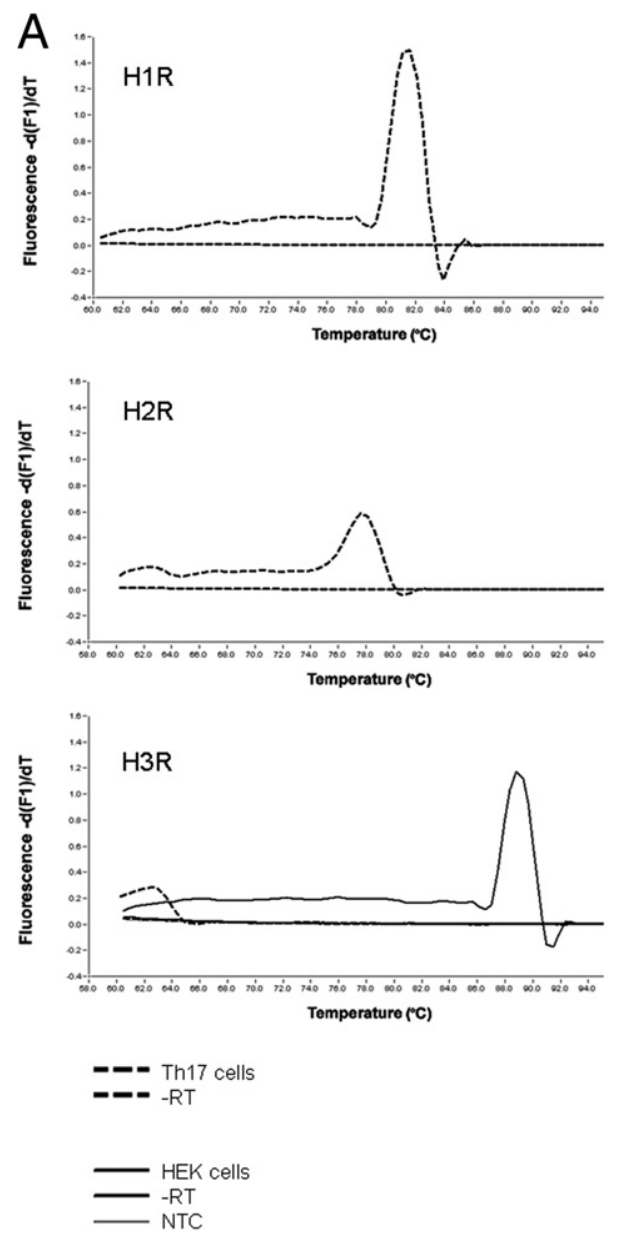

B
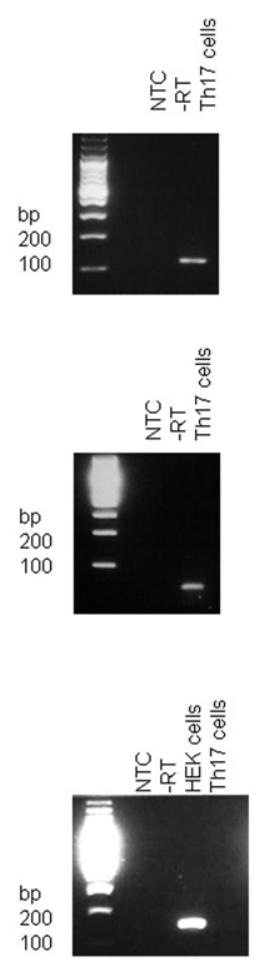
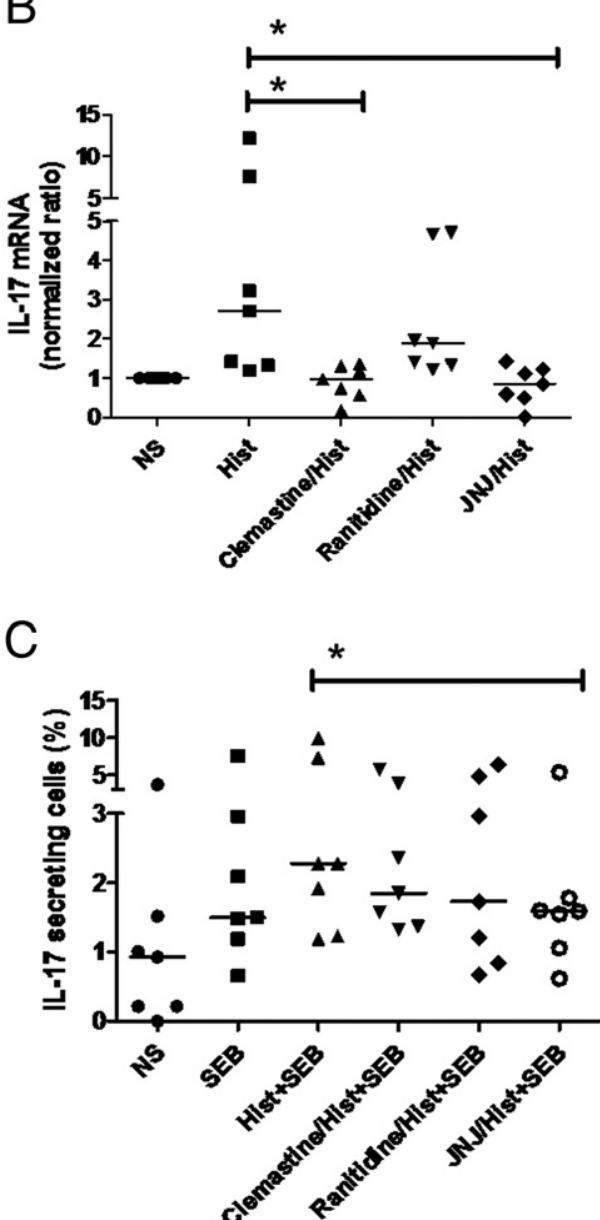

Figure 6. The up-regulation of IL-17 on histamine stimulation is mainly attributed to the H4R. Th17 cells also express the H1R and H2R on mRNA level but not the H3R. A: One representative real-time PCR analysis with melting peaks and agarose gel bands with the correct size of the amplified PCR products (H1R = 116 $\mathrm{bp} ; \mathrm{H} 2 \mathrm{R}=60 \mathrm{bp} ; \mathrm{H} 3 \mathrm{R}=150 \mathrm{bp}$ ) out of three independent experiments for each receptor is depicted. Th17 cells that reacted to histamine with an up-regulation of IL-17 were incubated with the H1R antagonist Clemastine $(10 \mu \mathrm{mol} / \mathrm{L})$, the H2R antagonist Ranitidine (10 $\mu \mathrm{mol} / \mathrm{L})$, or with the H4R antagonist JNJ7777120 (10 $\mu \mathrm{mol} / \mathrm{L}) 30$ minutes before histamine receptor stimulation. B: RNA was isolated after 6 hours and the relative expression levels of IL-17 mRNA were calculated by quantitative real-time PCR ( $n=7$ independent experiments, medians are indicated). For the detection on the single-cell level, SEB ( $1 \mu \mathrm{g} / \mathrm{mL}) \mathrm{was}$ added after histamine receptor stimulation for 16 hours. IL-17 was assessed by an IL-17 secretion assay via flow cytometry. C: Quadrant plot analysis with the percentage of $\mathrm{CD}^{+}$CCR6 $^{+}$IL-17 secreting cells is shown in ( $n=7$ independent experiments, medians are indicated). -RT indicates a negative control without reverse transcription. HEK cells, human embryonic kidney cells; NTC, nontemplate control. H3R-transfected HEK cells were used as positive control for H3R amplification. ${ }^{*} P<0.05$. 
level by means of flow cytometry with a selective H4R antibody directed against amino acids 194-303 of the $\mathrm{H} 4 \mathrm{R}$ as depicted in Figure 2C. The H4R is expressed on equal amounts on activated T cells and memory Th17 cells (Figure 2D). Since Th17 cells have been clearly identified in skin lesions of psoriasis ${ }^{11}$ we performed double immunofluorescence staining in skin samples of this common inflammatory skin disease and detected IL-17 positive cells expressing the H4R (Figure 3 ).

\section{Histamine and the H4R Agonist \\ 4-Methylhistamine Induce IL-17 in Human Memory Th17 Cells}

To evaluate functional effects of the H4R on Th17 cells, we stimulated the cells with histamine $(10 \mu \mathrm{mol} / \mathrm{L})$ and $4 \mathrm{MH}(10 \mu \mathrm{mol} / \mathrm{L})$ for 6 hours and assessed the influence on the production of the Th17 effector cytokines IL-17 and IL-22 as well as on the specific transcription factor RORC. Here we could show a significant up-regulation of IL-17 mRNA in Th17 cells on stimulation with histamine and $4 \mathrm{MH}$ (Figure $4 \mathrm{~A}$ and $\mathrm{B}$ ). No significant effects on the production of IL-22 and RORC mRNA were detected (Figure 4B).

To confirm the enhanced IL-17 production also on protein level, we stimulated the cells with histamine and $4 \mathrm{MH}(10 \mu \mathrm{mol} / \mathrm{L})$ for 2 hours, then SEB (as an activation factor, HLA-DR was expressed on these cells) was added for another 16 hours and a cytokine secretion assay was performed. In this assay the secreted IL-17 is trapped by an antibody that is also bound to the cell surface. The trapped IL-17 is then stained as an "artificial" surface molecule with another specific IL-17 antibody and the phenotype of the cytokine secreting cell can be detected by labeling with selected surface markers. The flow cytometric analysis of the stimulated cells revealed a moderate but significant increase of IL-17 secreting cells in the gated $\mathrm{CD} 4^{+} \mathrm{CCR}^{+}{ }^{+}$compartment on stimulation with $\mathrm{SEB}^{+}$histamine and $\mathrm{SEB}^{+} 4 \mathrm{MH}$ as induced by SEB alone (Figure $5 \mathrm{~A}$ and $\mathrm{B}$ ). Because Th17 cells also express the H1R and H2R, but not the H3R (Figure 6A), we proved with the appropriate antagonists against the H1R, H2R, and H4R if the up-regulation of IL-17 is specific for the H4R. Here we could show that the histamine induced up-regulation of IL-17 mRNA was blocked after pre-incubation of Th17 cells with the two $\mathrm{H} 1 \mathrm{R}$ and H4R antagonists (Figure 6B), whereas the increase of IL-17 secreting cells was selectively abrogated after blocking the H4R with JNJ77777120 (Figure 6C).

\section{Activation of the Transcription Factor AP-1 in Human Memory Th17 Cells}

We had previously shown that AP-1 is induced by H4R stimulation in human monocyte-derived dendritic cells and in Th2 polarized T cells. ${ }^{5,10}$ Here, we confirmed an activation of AP-1 in Th17 cells on stimulation. An increased AP-1 binding activity was induced by stimulation with histamine and with the specific H4R agonist $4 \mathrm{MH}$ as indicated by the shifted bands in the EMSA analysis. Induction of

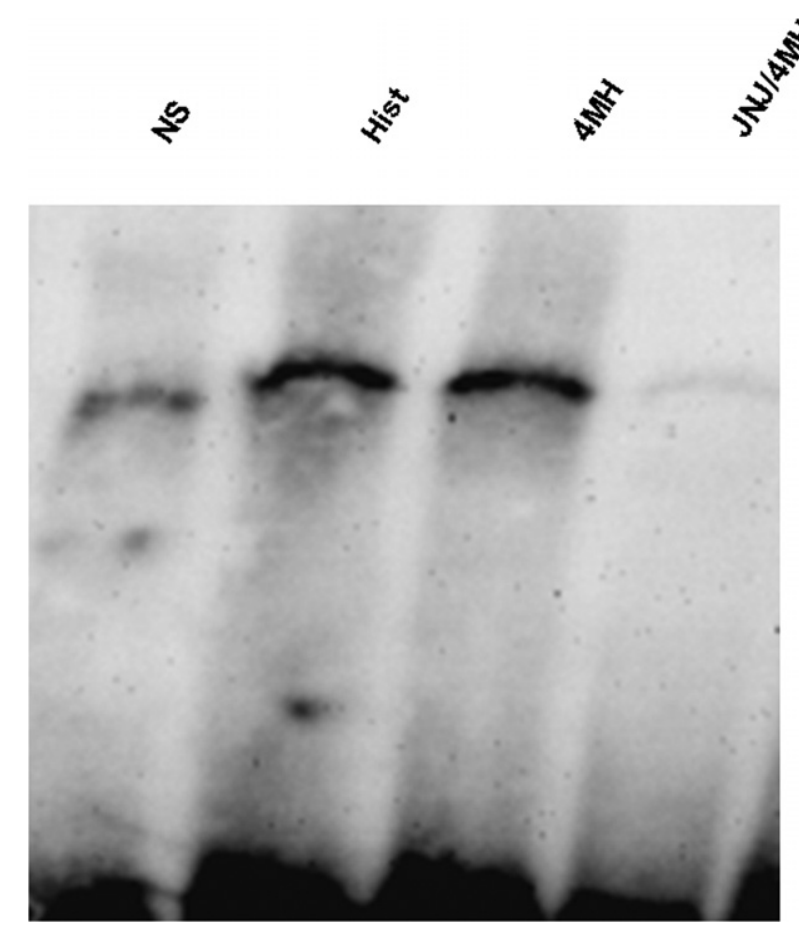

Figure 7. Histamine (Hist) and the H4R agonist $4 \mathrm{MH}$ induce the AP-1 transcription factor as demonstrated by the binding to labeled doublestranded oligonucleotides containing the AP-1 binding site. Th17 cells were stimulated with the indicated ligands for 30 minutes or left unstimulated (NS), nuclear extracts were prepared and analyzed for the presence of AP-1 transcription factor binding by electrophoretic mobility shift assay. Prestimulation with the H4R antagonist JNJ7777120 (JNJ) blocks the induction of AP-1. One representative experiment out of four is shown.

AP-1 via H4R could be blocked by pre-incubation with the H4R antagonist JNJ7777120 (Figure 7).

\section{Discussion}

Previously, it has been shown that the H4R is expressed on $\mathrm{CD} 4^{+} \mathrm{T}$ cells and exerts immunomodulatory effects on these cells. The H4R is up-regulated under Th2 conditions and promotes enhanced transcription levels of IL-31 mRNA. ${ }^{10}$ A study of Morgan et al ${ }^{22}$ reported about the potential of $\mathrm{H} 4 \mathrm{R}$ to induce migration of $\mathrm{CD} 4^{+} \mathrm{T}$ cells, which are enriched for $T$ cells with a regulatory phenotype expressing FoxP3. This was demonstrated in a murine model of allergic asthma and in vitro on human $\mathrm{CD} 4^{+}$ T cells. More recently, a new CD4 ${ }^{+}$T-cell subset, termed Th17 cells, has been identified and defined based on its capacity to express the pro-inflammatory and immunomodulatory effector cytokines IL-17, IL-22, and the transcription factor RORC. Th17 cells are mainly associated with host defense and autoimmune diseases, ${ }^{23}$ but recent reports demonstrate the presence of increased levels of IL-17 mRNA and T cells producing IL-17 in tissues of patients with psoriasis. ${ }^{11,12}$ In lesions of $A D$ that are characterized by intensely pruritic, erythematous papules and by marked infiltration of mononuclear cells, ${ }^{24}$ $\mathrm{IL}-17$ expression has been found to be increased in acute compared to chronic lesions of $A D{ }^{14,15}$ AD skin lesions contain a lower Th17 component compared with psoria- 
sis. ${ }^{17}$ In both common inflammatory skin diseases Th17 cells may have contact to histamine, which are released by mast cells and other cells during inflammatory reactions. ${ }^{25,26}$ However, the effect of Th17 polarizing cytokines on H4R expression and function was not known prior this study. Therefore, we examined these topics on Th17 cells. For this purpose we polarized isolated human memory $T$ cells with the combinations of the cytokines TGF- $\beta+$ IL-6 or IL- $1 \beta+$ IL-23. The conditions promoting human Th17 cell differentiation are not universally established, but recent data collectively indicated that IL-1 $\beta$ together with IL-6 or IL-23 are highly potent inducers of IL-17 secretion. ${ }^{12,20,21}$ In line with these investigations, we observed a greater effect on IL-17 secretion when the cells were stimulated by IL- $1 \beta+\mathrm{IL}-23$, whereas the combination TGF- $\beta+$ IL- 6 is less potent.

We next showed that polarized human memory Th17 cells express the H4R on the mRNA and protein level, as proved by means of real-time PCR and by flow cytometry. Moreover, immunofluorescence double color staining in skin lesions of psoriasis demonstrated the H4R expression on infiltrating IL-17 positive lymphocytes. After H4R stimulation we observed increased IL-17 mRNA and enhanced secretion of IL-17 protein on the single-cell level in polarized human memory Th17 cells, whereas the production of IL-22 and RORC mRNA remained unaffected. Although a dual H1R and H4R mediated effect for the up-regulation of IL-17 mRNA was observed, the increase of IL-17 secreting cells was selectively blocked by preincubation with the H4R antagonist JNJ7777120, proving that the effect is mainly attributed to the H4R. Because IL-17 is a cytokine with a broad range of functions, the enhanced production on histamine stimulation can have major impact on the immunological responses taking part in inflammatory skin diseases. IL-17 released from Th17 effector $\mathrm{T}$ cells has a potential role in bridging the adaptive and the innate immune system. ${ }^{16} \mathrm{IL}-17$ is known to co-ordinate the immune response by promoting eosinophils to produce enhanced amounts of CXCL1 and $\mathrm{IL}-8,{ }^{27}$ by recruiting neutrophils and by stimulating the production of pro-inflammatory cytokines, chemokines, and innate defense proteins from a variety of immune and nonimmune cells, ${ }^{16,18,23}$ which results in the perpetuation of inflammation. In addition, IL-17 is able to modulate B-cell function and antibody production. ${ }^{28}$ Confirming our data, the levels of diverse pro-inflammatory cytokines and chemokines, including IL-4, IL-5, and IL-17, were inhibited by treatment with H4R antagonists in a Th2 cell mediated murine skin model that mimics several features of $\mathrm{AD}^{29}$ Interestingly, IL-22 mRNA induction was not significantly influenced by stimulation of $\mathrm{H} 4 \mathrm{R}$. Our observation indicates that although IL-22 and IL-17 can be produced by the same Th17 cells, regulation of their production on the molecular level may be distinct. In support of this, studies from several groups also demonstrate differences between the induction of these two Th17 effector cytokines. ${ }^{30,31}$

Owing to our findings in previous studies that $\mathrm{H} 4 \mathrm{R}$ signaling is able to induce AP-1 in monocyte-derived dendritic cells ${ }^{5}$ and Th2 cells, ${ }^{10}$ we decided to investigate whether AP-1 is activated via H4R in Th17 cells. In agreement with our former results we could show that histamine and the H4R agonist $4 \mathrm{MH}$ induce DNA binding of the transcription factor AP-1 in Th17 cells. Prestimulation with a selective H4R antagonist abolished this effect.

The discovery of Th17 cells as a distinct lineage of T cells led to the observation that development and IL-17 production are mainly controlled by the transcription factor RORC. ${ }^{32,33}$ Of note, the expression of RORC and IL-17 in human Th17 cells is not as tightly linked as they are in mouse cells. ${ }^{34}$ Moreover, it is likely that combination interactions of multiple transcription factors RORC, activated STAT3, and interferon regulatory factor 4 - promote Th17 development. ${ }^{35}$ The involvement of $\mathrm{NF}-\kappa \mathrm{B}$ or $\mathrm{AP}-1$ in this network remains still a matter of debate. ${ }^{34}$ The $\mathrm{H} 4 \mathrm{R}$, as a $\mathrm{G} \alpha_{\mathrm{i} / \mathrm{s}}$-coupled receptor, is known to activate mitogen-activated protein kinase pathways $^{36}$ that are upstream events of AP-1 activation. ${ }^{37}$ In this context our investigations on monocytes, ${ }^{5}$ Th2 cells, ${ }^{10}$ and Th17 cells (this study) suggest that the activation of the transcription factor AP-1 might be a common pathway in $\mathrm{H} 4 \mathrm{R}$ signaling in diverse immune cells.

Thus, H4R has both pathological and protective purposes during inflammation on different subsets of human T cells, which points toward a complex role of the H4R. The chemoattractive effect of histamine on regulatory $T$ cells provides evidence for anti-inflammatory properties. ${ }^{22}$ On the other hand, H4R may contribute to an exacerbation of inflammatory skin diseases by stimulating Th2 cells to up-regulate the pruritic cytokine $\mathrm{IL}-31^{10}$ and Th17 cells to release enhanced amounts of the immunomodulatory cytokine IL-17 as demonstrated in this work.

The challenge in future research is to further elucidate the beneficial and pathological effects of the H4R and to figure out the potential use of H4R agonists or antagonists in the treatment of inflammatory diseases.

\section{References}

1. Nakamura $\mathrm{T}$, Itadani $\mathrm{H}$, Hidaka $\mathrm{Y}$, Ohta M, Tanaka $\mathrm{K}$ : Molecular cloning and characterization of a new human histamine receptor, HH4R. Biochem Biophys Res Commun 2000, 279:615-620

2. Oda T, Morikawa N, Saito Y, Masuho Y, Matsumoto S: Molecular cloning and characterization of a novel type of histamine receptor preferentially expressed in leukocytes. J Biol Chem 2000, 275:3678136786

3. Hofstra CL, Desai PJ, Thurmond RL, Fung-Leung WP: Histamine H4 receptor mediates chemotaxis and calcium mobilization of mast cells. J Pharmacol Exp Ther 2003, 305:1212-1221

4. Ling P, Ngo K, Nguyen S, Thurmond RL, Edwards JP, Karlsson L, Fung-Leung WP: Histamine $\mathrm{H} 4$ receptor mediates eosinophil chemotaxis with cell shape change and adhesion molecule upregulation. Br J Pharmacol 2004, 142:161-171

5. Gutzmer R, Diestel C, Mommert S, Kother B, Stark H, Wittmann M Werfel T: Histamine $\mathrm{H} 4$ receptor stimulation suppresses IL-12p70 production and mediates chemotaxis in human monocyte-derived dendritic cells. J Immunol 2005, 174:5224-5232

6. Damaj BB, Becerra CB, Esber HJ, Wen Y, Maghazachi AA: Functional expression of $\mathrm{H} 4$ histamine receptor in human natural killer cells, monocytes, and dendritic cells. J Immunol 2007, 179:7907-7915

7. Gschwandtner M, Schakel K, Werfel T, Gutzmer R: Histamine H(4) receptor activation on human slan-dendritic cells down-regulates their pro-inflammatory capacity. Immunology 2011, 132:49-56 
8. Dijkstra D, Leurs R, Chazot P, Shenton FC, Stark H, Werfel T, Gutzmer R: Histamine downregulates monocyte CCL2 production through the histamine H4 receptor. J Allergy Clin Immunol 2007, 120:300-307

9. Gschwandtner M, Rossbach K, Dijkstra D, Baumer W, Kietzmann M, Stark H, Werfel T, Gutzmer R: Murine and human Langerhans cells express a functional histamine $\mathrm{H} 4$ receptor: modulation of cell migration and function. Allergy 2010, 65:840-849

10. Gutzmer R, Mommert S, Gschwandtner M, Zwingmann K, Stark H, Werfel T: The histamine $\mathrm{H} 4$ receptor is functionally expressed on $\mathrm{T}(\mathrm{H}) 2$ cells. J Allergy Clin Immunol 2009, 123:619-625

11. Lowes MA, Kikuchi T, Fuentes-Duculan J, Cardinale I, Zaba LC, Haider AS, Bowman EP, Krueger JG: Psoriasis vulgaris lesions contain discrete populations of Th1 and Th17 T cells. J Invest Dermatol 2008, 128:1207-1211

12. Wilson NJ, Boniface K, Chan JR, McKenzie BS, Blumenschein WM, Mattson JD, Basham B, Smith K, Chen T, Morel F, Lecron JC, Kastelein RA, Cua DJ, McClanahan TK, Bowman EP, de Waal Malefyt R: Development, cytokine profile and function of human interleukin 17 producing helper T cells. Nat Immunol 2007, 8:950-957

13. Kagami S, Rizzo HL, Lee JJ, Koguchi Y, Blauvelt A: Circulating Th17. Th22, and Th1 cells are increased in psoriasis $\mathrm{J}$ Invest Dermatol 2010, 130:1373-1383

14. Toda M, Leung DY, Molet S, Boguniewicz M, Taha R, Christodoulopoulos P, Fukuda T, Elias JA, Hamid QA: Polarized in vivo expression of IL-11 and IL-17 between acute and chronic skin lesions. J Allergy Clin Immunol 2003, 111:875-881

15. Koga C, Kabashima K, Shiraishi N, Kobayashi M, Tokura Y: Possible pathogenic role of Th17 cells for atopic dermatitis. J Invest Dermatol 2008, 128:2625-2630

16. Eyerich K, Pennino D, Scarponi C, Foerster S, Nasorri F, Behrendt $H$, Ring J, Traidl-Hoffmann C, Albanesi C, Cavani A: IL-17 in atopic eczema: linking allergen-specific adaptive and microbial-triggered innate immune response. J Allergy Clin Immunol 2009, 123:59-66.e4

17. Guttman-Yassky E, Lowes MA, Fuentes-Duculan J, Zaba LC, Cardinale I, Nograles KE, Khatcherian A, Novitskaya I, Carucci JA, Bergman R, Krueger JG: Low expression of the IL-23/Th17 pathway in atopic dermatitis compared to psoriasis. J Immunol 2008, 181:74207427

18. Liang SC, Tan XY, Luxenberg DP, Karim R, Dunussi-Joannopoulos K, Collins M, Fouser LA: Interleukin (IL)-22 and IL-17 are coexpressed by Th17 cells and cooperatively enhance expression of antimicrobial peptides. J Exp Med 2006, 203:2271-2279

19. Nograles KE, Suarez-Farinas M, Shemer A, Fuentes-Duculan J, Chiricozzi A, Cardinale I, Zaba LC, Kikuchi T, Ramon M, Bergman R, Krueger JG, Guttman-Yassky E: Atopic dermatitis keratinocytes exhibit normal $\mathrm{T}(\mathrm{H}) 17$ cytokine responses. J Allergy Clin Immunol 2010 , 125:744-746,746.e1-746.e2

20. Liu H, Rohowsky-Kochan C: Regulation of IL-17 in human CCR6 ${ }^{+}$ effector memory T cells. J Immunol 2008, 180:7948-7957

21. Yang L, Anderson DE, Baecher-Allan C, Hastings WD, Bettelli E, Oukka M, Kuchroo VK, Hafler DA: IL-21 and TGF-beta are required for differentiation of human $\mathrm{T}(\mathrm{H}) 17$ cells. Nature 2008, 454:350-352

22. Morgan RK, McAllister B, Cross L, Green DS, Kornfeld H, Center DM Cruikshank WW: Histamine 4 receptor activation induces recruitment of $\mathrm{FoxP}^{+} \mathrm{T}$ cells and inhibits allergic asthma in a murine model. $\mathrm{J}$ Immunol 2007, 178:8081-8089
23. Ouyang W, Kolls JK, Zheng Y: The biological functions of T helper 17 cell effector cytokines in inflammation. Immunity 2008, 28:454-467

24. Werfel T: The role of leukocytes, keratinocytes, and allergen-specific IgE in the development of atopic dermatitis. J Invest Dermatol 2009, 129:1878-1891

25. Krogstad AL, Lonnroth $P$, Larson G, Wallin BG: Increased interstitial histamine concentration in the psoriatic plaque. J Invest Dermatol 1997, 109:632-635

26. Stander S, Steinhoff M: Pathophysiology of pruritus in atopic dermatitis: an overview. Exp Dermatol 2002, 11:12-24

27. Cheung PF, Wong CK, Lam CW: Molecular mechanisms of cytokine and chemokine release from eosinophils activated by IL-17A. IL-17F, and IL-23: implication for Th17 lymphocytes-mediated allergic inflammation. J Immunol 2008, 180:5625-5635

28. Doreau A, Belot A, Bastid J, Riche B, Trescol-Biemont MC, Ranchin B, Fabien N, Cochat P, Pouteil-Noble C, Trolliet P, Durieu I, Tebib J, Kassai B, Ansieau S, Puisieux A, Eliaou JF, Bonnefoy-Berard N: Interleukin 17 acts in synergy with B cell-activating factor to influence B cell biology and the pathophysiology of systemic lupus erythematosus. Nat Immunol 2009, 10:778-785

29. Cowden JM, Zhang M, Dunford PJ, Thurmond RL: The histamine H(4) receptor mediates inflammation and pruritus in Th2-dependent dermal inflammation. J Invest Dermatol 2010, 130:1023-1033

30. Zheng Y, Danilenko DM, Valdez P, Kasman I, Eastham-Anderson J, Wu J, Ouyang W: Interleukin-22, a T(H)17 cytokine, mediates IL-23induced dermal inflammation and acanthosis. Nature 2007, 445:648651

31. Chen Z, Tato CM, Muul L, Laurence A, O'Shea JJ: Distinct regulation of interleukin-17 in human $\mathrm{T}$ helper lymphocytes. Arthritis Rheum 2007, 56:2936-2946

32. Ivanov II, McKenzie BS, Zhou L, Tadokoro CE, Lepelley A, Lafaille JJ, Cua DJ, Littman DR: The orphan nuclear receptor ROR $\gamma$ t directs the differentiation program of proinflammatory $\mathrm{IL}-17^{+} \mathrm{T}$ helper cells. Cell 2006, 126:1121-1133

33. Crome $S Q$, Wang AY, Kang CY, Levings MK: The role of retinoic acid-related orphan receptor variant 2 and IL-17 in the development and function of human CD4 ${ }^{+}$T cells. Eur J Immunol 2009, 39:14801493

34. Chen Z, Laurence A, O'Shea JJ: Signal transduction pathways and transcriptional regulation in the control of Th17 differentiation. Semin Immunol 2007, 19:400-408

35. Ivanov II, Zhou L, Littman DR: Transcriptional regulation of Th17 cel differentiation. Semin Immunol 2007, 19:409-417

36. Morse KL, Behan J, Laz TM, West RE, Jr, Greenfeder SA, Anthes JC Umland S, Wan Y, Hipkin RW, Gonsiorek W, Shin N, Gustafson EL, Qiao X, Wang S, Hedrick JA, Greene J, Bayne M, Monsma FJ, Jr: Cloning and characterization of a novel human histamine receptor J Pharmacol Exp Ther 2001, 296:1058-1066

37. Matesanz N, Lafuente N, Azcutia V, Martin D, Cuadrado A, Nevado J, Rodriguez-Manas L, Sanchez-Ferrer CF, Peiro C: Xanthine oxidasederived extracellular superoxide anions stimulate activator protein 1 activity and hypertrophy in human vascular smooth muscle via c-Jun $\mathrm{N}$-terminal kinase and p38 mitogen-activated protein kinases. J Hypertens 2007, 25:609-618 